\title{
DIGITAL CURRENCIES AND THEIR POTENTIAL TO DISRUPT AND REPLACE FIAT MONEY: THE CASE OF BITCOINS
}

\author{
Virginia Kirigo Wachira ${ }^{1}$, \\ Esther Wanjiru Wachira ${ }^{2 \mathrm{i}}$ \\ ${ }^{1}$ School of Business and Economics, \\ Meru University of Science and Technology, \\ Kenya \\ ${ }^{2} \mathrm{PhD}$ Candidate, \\ Faculty of Business and Economics, \\ University of Pecs, \\ Hungary
}

\begin{abstract}
:
This paper aims to investigate how digital currencies have caused a drastic evolution, especially in the payment sector. It aims to further studies on how bitcoin is the most conspicuous digital currency and is perceived as disruptive innovation with the potential of replacing fiat currency. The study was employed through a case study to examine whether bitcoins are disruptive innovation or a threat to the Central Banks and Fiat money. The study adopted a mixed approach research design by using qualitative and quantitative research approaches. The literature reviewed journals were published in credible journals in various databases. The Time series analysis approach was used to forecast the future prices of bitcoins. The study used an in-sample and out-of-sample time series forecasting using the Gretl software. The ARIMA $(1,2,1)$ Model was found to be a good fit with 85\% accuracy (the Mean Absolute Percentage Error -MAPE was 15\%) to forecast the future of bitcoin prices. The outcome of the forecast suggested that bitcoin price will have a gradual but insignificant increase. The results of this study also suggest that bitcoins fail to fulfill the functions of money as a store of value, medium of exchange, and unit of account. This is attributed to high price volatility, lack of centralization, and exposure to hackers and fraudsters. The study further suggests that bitcoins are not disruptive innovations and do not pose any threat to the Central banks and the Fiat currency in the future. The results support that bitcoin can benefit the community as well as attracting investors as a speculative investment mainly because the bitcoins are limited in transactions. The study recommends more research on the potential impact of the Central bank's digital currencies on National and Global currencies particularly because China launched its digital Yuan recently.
\end{abstract}

JEL: G21; E58; E51; 031; C10

i Correspondence: email vkwachira2012@gmail.com, e.wachira2012@gmail.com 
Keywords: digital currency, bitcoins, fiat money, disruptive innovations, disruptive technologies

\section{Introduction}

Digital currencies have increased the use of new technologies. Today, the world is witnessing huge growth and development of disruptive technologies. In particular, digitization has prompted to doing business through the internet leading to a drastic decline in transaction costs, stimulating the development and demand for new modes of electronic payment. The new electronic payment revolution such as digital money, or digital cash, has improved the effectiveness of the traditional payment methods. Due to their capacity to foster the restructured supply of digital goods and services, customer behavior, tastes, and preferences have been deeply felt by financial institutions. Nowadays customers prefer the option of quick, cost-effective, and convenient financial services.

The development of digital currencies such as mobile payments, PayPal, Bitcoin, and blockchain has led to a new innovative means of exchange, utilizing and enhancing internet transactions in the financial sector as a means for improving liquidity. Digital currencies have caused a drastic evolution in the payment system with their main aim being "to improve the efficiency of the traditional payment methods" (Tatjana, 2018). Innovation in digital currencies has been attributed to the advancement of technology and the accessibility to the internet making the world a global village. According to Narayanan(2020), digital currencies evolution has led to an increase in demand for more flexible, time-saving, and cheaper transactions through the internet or a click of mobile phones. Digital currencies represent a new sensation in the financial sector globally as they provide instant P2P transfers of value (Ciaian et al., 2018 and Brunnermeier \& James, 2019).

Current literature defines digital currency as a currency that is stored and transferred electronically (Wagner 2014; and Rose, 2015). The European Banking Authority also defined digital currencies as the digital representation of value that is neither issued by the Central bank nor attached to real money but is accepted as a mode of payment, can be stored, traded, or transferred electronically (EBA, 2014). Additionally, Narayanan (2020), defined digital currencies as any form of currency not available in physical form but rather in an electronic form. Digital currencies include Bitcoin, Ethereum, Dash, BitShares, LiteCoin, PeerCoin, Ripple, DogeCoin (Ciaian et al., 2018; Tatjana, 2018; Saito \& Iwamura, 2019).

Digital currencies have provided alternative money and investment opportunity outside centralized financial institutions. Moreover, current literature suggests that global digital currencies represent a new phenomenon (Giudici et al., 2020; Baur \& Dimpfl, 2021) on global financial markets and have gained their roots in various forms. For instance, WeChat was launched in China in 2011. WeChat enables users to pay bills, use money transfer services, and mobile payments using WeChat Pay. Additionally, 
Virginia Kirigo Wachira, Esther Wanjiru Wachira

DIGITAL CURRENCIES AND THEIR POTENTIAL TO

DISRUPT AND REPLACE FIAT MONEY: THE CASE OF BITCOINS

Alipay was also launched in 2015 in China to provide services such as mobile payment, money transfers and also enables users to order goods and services. In Africa, M-Pesa was launched in 2007 by the giant telecommunication operator in Kenya. Brunnermeier \& James (2019) also noted that Facebook has announced plans to introduce Libra which will be attached to a "basket of official currencies". One important fact of using digital currencies as compared to other fiat currencies is that the digital currencies are more flexible (Böhme et al., 2015), provide greater privacy, and protects against inflation (Moore, 2013), low costs of transaction (Peters \& Panayi, 2016) making them the least expensive (Narayanan, 2020), increased speed of transactions and improved security (Abramova \& Böhme, 2016; Fadele 2016).

Considering the above benefits, some economies have accepted the emerging digital currencies as a valid currency and means of payment (Tatjana, 2018; Saito \& Iwamura, 2019). Countries such as Japan and Germany recognized Bitcoin as a legal currency in April 2017 and March 2018 respectively (Frascaroli, 2019). The acceptance of digital currencies, therefore, stimulates economic growth as the central banks are forced to be innovative to compete with other central banks and private actors (Ally et al., 2015). The digital currencies signify innovations in the form of a new currency that is generally accepted as a medium of exchange used in the payment systems (Robleh et al., 2014).

Recent research suggested that bitcoin was the first digital currency to be decentralized and continues to be the most widely used online currency (Presthus \& O'Malley, 2017). Hence, its success Bitcoin as a digital currency has attracted the attention of many academic scholars who have investigated the blockchains and digital currencies, their intrinsic value, relationship with the banking sector as well as their implications for society (Chan et al., 2017; Fiammetta \& Piazza, 2017; Gilbert \& Loi, 2018 and White et al., 2020), Customer awareness and adoption of the digital currencies (Presthus \& O'Malley, 2017; Eigbe, 2018). This study aims to understand the existing literature on digital currencies and in particular the bitcoins. The study was based on how essential bitcoins can be as disruptive innovations, bitcoins standing potential to be considered as money, and finally, Government perspective over bitcoins being a threat to the Central banks and fiat money. The study was based on existing literature reviews and time series analysis to forecast the future prices of the bitcoin.

\section{Literature Review}

\subsection{Digital Currencies}

Digital currency has steadily grown with the advancement of technology and may displace hard currencies and paper checks. Digital currency is therefore a recent advance of technology that has led to new forms of money. Digital currencies are issued by a software protocol or in a decentralized technique using a computer system. They are not a liability of individuals or institutions since they are not issued by a central bank like notes banks, or commercial banks like deposit accounts. Additionally, digital currencies are not supported by the Government. Recently the economies and the central banks 
globally have been monitoring the development of digital currencies as well their implications. Despite financial innovations in the banks, the existence of dynamic and business uncertainty has raised concern about whether central banks should issue digital currency that would be used by the general public or not. According to a study by Nakamoto (2009), the best known and widely used digital currency is bitcoin which was launched as a peer-to-peer payment system in 2009.

\subsubsection{Bitcoin}

Bitcoin is the most conspicuous and widely recognized digital currency (Roussou \& Stiakakis, 2016; and Chan et al., 2017) witnessing continuous growth in terms of transaction volume over time. Bitcoin was created as an open-source program in 2008 and introduced in 2009 by Satoshi Nakamoto (Nakamoto2009). Bitcoin is a decentralized system, based on a peer-to-peer network (Abramova \& Böhme, 2016). In support Presthus and O'Malley (2017) states that bitcoin is a peer-to-peer electronic cash system that is made up of miners, blockchain, and wallets as three key components. bitcoins are recorded as transactions from one owner to the next by use of public key transactions that are readable and accessible to every user (Böhme et al., 2015). Consequently, new transactions are grouped into a block. Blockchain is the grouping of transactions in blocks with the chains formed from these groups acting as the accepted transaction history(Peters \& Panayi, 2016). The blockchain is updated approximately every 10 minutes (Presthus \& O'Malley, 2017; Böhme et al., 2015). On the other hand, the miner component secures the transactions hence preventing the duplication of transactions (Presthus \& O'Malley, 2017), therefore, based on the record of transactions in the past blocks, the network verifies the validity of new transactions (Peters \& Panayi, 2016). The wallet component keeps a copy of the blockchain (Presthus \& O'Malley, 2017). According to Ally et al., (2015), Bitcoin is an electronic payment system that enables direct transactions using the internet without an intermediary.

Bitcoins unlike Fiat money does not rely on authorities or financial intermediaries (Abramova \& Böhme, 2016). Hence anyone can create a bitcoin account without necessarily providing a real name or following any set procedures (Böhme et al., 2015). However, despite the various benefits associated with digital currencies, they have also attracted a large share of negative attention from academic researchers and scholars. Saito \& Iwamura (2019) argues that these digital currencies should not be considered as the perfect mode of payment due to the fluctuations in their market prices. The unstable market prices may eventually lead to hoarding as speculative customers expect a rise in prices soon (Graf, 2013; Cheah \& Fry, 2015 and Abramova \& Böhme, 2016). Additionally, it is difficult for retailers to accept digital currencies as a mode of payment with the full knowledge that their value may depreciate anytime (Rose, 2015). Moreover, (Moore, 2013) argues that digital currencies expose consumers to various risks such as exchange rate risks, irreversibility of transactions (Böhme et al., 2015), and exposure to hackers. According to (Böhme et al., 2015), due to the anonymity nature of digital currencies, there is a high tendency for them to be used by criminals, especially for money laundering 
Virginia Kirigo Wachira, Esther Wanjiru Wachira

DIGITAL CURRENCIES AND THEIR POTENTIAL TO

DISRUPT AND REPLACE FIAT MONEY: THE CASE OF BITCOINS

activities. According to (Abramova \& Böhme, 2016), due to these risks, digital currencies especially bitcoin, has not effectively attracted a wide base of customers.

\subsection{Bitcoins as Disruptive Innovations}

The literature of Bitcoins as disruptive innovation is still in the early stage and remains controversial (Dannels, 2004; Markides, 2006 and Yu \& Hang, 2010). Disruption innovation is an innovation that causes alteration of how companies compete in the market through changing their performance metrics (Dannels, 2004). Disruptive innovations can also be viewed as innovations that employ the technology of doing things that disrupt the traditional business practices and consequently affecting the industry and the market at large.

However, Dannels (2004), stated that disruptive innovation has become overused to be a principle. Christensen (1997), who is credited with spreading the awareness of disruptive technologies, pointed out a few features that qualified to make technologies disruptive. The first was that the technologies would enable something that was deemed impossible previously. Second, disruptive technologies are ignored and dismissed by companies and clients typically because they are small. Third, disruptive technologies have a product life cycle which is divided into four phases (functionality, reliability, convenience, and price) (Christensen, 1997). While, Christensen, Rayno, and McDonald (2015) support these concepts of disruption others generally criticize the concepts as a process that lacks measurability of disruptive innovation (Govindarajan and Kopalle, 2006). Additionally, Tellis, (2016) argues that today most people look at Bitcoin as impractical curiosity and Christensen's theory does not allow for clear differentiation between disruptive technologies where small companies with fewer resources successfully challenge established businesses. According to Christensen et al., (2015), the established businesses focus on improving their businesses, paying attention to a particular group of customers who are considered to be more profitable, and ignoring another group of customers. Therefore, disruptive companies now focus on the ignored segment by delivering a more suitable product or service at a lower price. The existing companies at this stage do not pay attention to the changes in the market thus giving leeway to the new entrants to scale upwards in the market ladder by "delivering the performance that incumbents' mainstream customers require while preserving the advantages that drove their early success". This eventually leads to the new entrants disrupting or even "un sitting" the established companies (Christensen et al., 2015).

Some academic scholars view digital currencies as a financial disruptor as they provide alternative money, investment opportunities, and cheaper transaction costs (Moore, 2013; Böhme et al., 2015; Roussou \& Stiakakis, 2016; Peters \& Panayi, 2016; Ciaian et al., 2018). Due to their low transaction costs, digital currencies have the potential to disrupt money remittance globally (Peters \& Panayi, 2016), and reshape the nature of currency competition (Brunnermeier \& James, 2019). Presthus \& O'Malley (2017) study revealed that digital currencies can be termed as disruptive innovations if they are communicated through various channels, match the innovator's category in the S-curve 
and must be accepted by all customers. According to Tatjana(2018), with the regulation of Central banks, digital currencies are likely to replace the traditional means of payment. However, regulating the digital currencies would reduce on the privacy aspect that they ride on and becoming less appealing to the customers (Tatjana, 2018). Bitcoin has the highest disruptive impact compared to the other digital currencies in the market (Frascaroli, 2019).

\subsection{Bitcoin as Money}

Although Bitcoins work just like real money scholars states that it has some distinctions with real currencies. Bucherer et al. (2012) explore bitcoin as a Blockchain, that changes the banking sector process, such as elimination of financial intermediary, speed of international transactions, and cost of the transaction. Mural (2013) argues that bitcoin is a currency of the new generation issued by private parties and circulates as a new generation and creates people's confidence. A study by Mark (2011) revealed that there is no actual coin in the Bitcoin system. The study also argues that digital currency is different from government currency as it circulates through the internet by private parties. Dwyer (2014), in support, stated that digital currency such as Bitcoin is a transaction system that consists of a list of inputs each representing a new coin and outputs scripts. However, every coin can be traced back to its origin.

The economics viewpoint that, there are three major functions of money namely medium of exchange, store of value, and unit of account ${ }^{\mathrm{ii}}$. Other scholars expanded the functions of money to six namely; medium of exchange, measure of value, store of value, basis of credit, unit of account, and standard of postponed paymentiii. Recent researchers such as Robleh et al., (2014); Tatjana, (2018); Narayanan, (2020) have also outlined the mode of exchange, the unit of account, and the store of value as the functions of money. Their studies examined the blockchain to determine the dependency of digital currencies and whether Bitcoin can be considered as money.

Realistic insight into the adoption of bitcoin as money revealed that bitcoin failed to meet the criteria of a currency which includes functions such as a store of value, medium of exchange, and unit of account (Yermack, 2013). To defend this view, the author pointed out the high volatility, very few transactions, exposure to theft and hackers, and finally non-intervention of the Central bank. However, it is widely understood that bitcoin was more of a speculative investment rather than a currency (Yermack, 2013). Fred Ersham the founder of Coinbase estimated that $80 \%$ of activity in

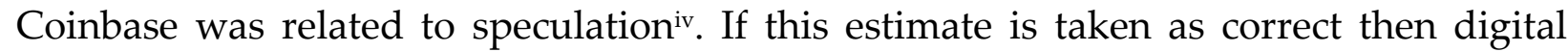
currencies lack key demand, central authority and their future is uncertain hence their

\footnotetext{
iihttps://opentextbc.ca/principlesofeconomics/chapter/27-1-defining-money-by-its-functions/ Accessed on $11^{\text {th }}$ November 2020

iiihttps://www.economicsdiscussion.net/money/functions-money/top-6-functions-of-moneydiscussed/12710 Accessed November 10, 2020

https://www.goldmansachs.com/investor-relations/financials/archived/annual-reports/2014-annualreport/ Accessed on 29th March 2021
} 
function as a store of value is largely dependent on demand over time (Robleh et al., 2014).

The difficulty of procuring bitcoin is one obstacle to bitcoin as a medium of exchange. To purchase the bitcoins, the customer must source bitcoins online as it is now dominated by supercomputers requiring massive capital investments the find a way of storing them. In this case, the number of transactions conducted over time is an indicative measure of digital currencies as a medium of exchange. Additionally, credit cards or PayPal cannot be used to purchase bitcoins instead the buyer makes a bank transfer or links an existing bank account to the exchange. This makes the existing bitcoin exchange have low liquidity, significant bid-ask spreads, and a certain amount of execution and custody risk (Yermack, 2013).

Finally, for a currency to be used as a unit of account consumers must compare the prices of alternative retail goods. Wu \& Pandey, (2014) noted that bitcoins are characterized by several obstacles in becoming a unit of account. One problem arises from high price volatility that makes it poor in the store of value function while its limited daily transactions make it a poor medium of exchange. In support Popper (2013) as cited by Rose (2015), argued that the high volatility characteristic and highly inelastic supply of digital currencies act as a hindrance to their general acceptance as a medium of exchange. Additionally, lack of Government backing or central control of digital currencies acts as a hindrance to the currencies to perform the store of the value function (Rose, 2015).

\subsection{Bitcoin as a threat to the Central Bank and Fiat Money}

Bitcoin is the best-known and most widely used digital currencies (Nakamoto, 2008). Bitcoin was launched in 2009 as a peer-to-peer payment for online purchases (Robleh et al., 2014). Although bitcoin is considered as a digital currency to overcome the limits of fiat money there are some bottlenecks related to its sustainability. First bitcoins exist in a different ecological system known as the digital ecosystem that consists of all hardware devices, program files, and data files that one user can share with other users (Giungato, 2017). Second, the social elements that lead to the creation and use of digital elements as "non-material technological objects"(Faulkner \& Runde, 2014). However, as bitcoin have an economic value its computing capacity defines the scarcity of the good and increasing of its economic value. Nelson (2018), examined the financial stability and monetary policy issues associated with digital currencies and found no significant relationship between digital currency with the potential threat to complicate the ability of Central banks in controlling inflation or regulating the business cycle. Fiat money (sovereign currencies) is issued by the central banks. A recent study by Stevens, (2017), argued that substituting fiat money with digital currencies would reduce the Central Bank's control over monetary conditions significantly. This has made the central banks increasingly keep their currencies attractive. Niepelt (2015) posits that the central banks should let the general public access electronic money and not just the financial institutions. However, Nelson (2018) stated that it is unthinkable that a digital currency would be adopted 
instead of physical cash even in countries that have lost faith and trust in the Central banks.

Following a report by the European Central Bank (2015), that "bitcoins are not full forms of money" but can be seen as alternates of coins and banknotes, especially in the payment space, Ciaian et al., (2016) argued that bitcoins cannot complete with the fiat money so long as their prices are largely motivated by speculative investments. At the same time Stevens, (2017), posits that price volatility and lack of regulatory status from authorities limit the digital currencies from becoming widespread. Hence bitcoin as a digital currency concept was just a myth since a currency can't be digitized and are "accounting systems for non-existent assets" (Grym, 2018). However, recent research by White et al., (2020), indicated that the behavior of bitcoins is similar to those of a technologically based product and cannot be termed as currencies as they "fail as a unit of account".

Ally et al., (2015) and Brunnermeier \& James (2019), argued that the emergence of digital currencies will disrupt the functions of money hence making competition steeper for the real currency. This is only possible if the digital currency will be controlled and reinforced by the Central banks (Narayanan, 2020).

\section{Material and Methods}

The study adopted a mixed approach research design by using qualitative and quantitative research components. The qualitative research aspect was used to answer the questions "Are bitcoins disruptive innovations?" "Are bitcoins money?". The qualitative research aspect was achieved through reviewing past literature from journals published in credible journals in various databases such as Web of Science, Scopus, Science Direct, EBSCO host, and JSTOR. The quantitative research approach was used in the attempt to answer the question of whether bitcoin will replace fiat money, the study used time series analysis to forecast the future prices of the bitcoin. The data was obtained from https://www.coindesk.com/price/bitcoin and https://www.statista.co

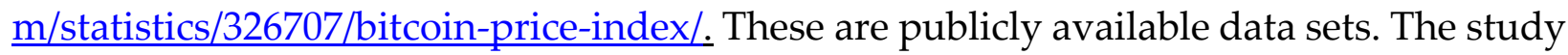
used the closing prices of Bitcoin between October 2013 to October 2020.

\subsection{Research Model}

The study used ARIMA Model to forecast the bitcoin prices. ARIMA is the short name of AutoRegressive (denoted as AR), Integrated (denoted as I) Moving Average (denoted as MR).

The general ARIMA equation is:

$\mathrm{y}^{\prime}=\mathrm{c}+\phi_{1} \mathrm{y}_{\mathrm{t}-1}^{\prime}+\cdots+\phi_{\mathrm{p}} \mathrm{y}_{\mathrm{t}-\mathrm{p}}+\theta_{1} \varepsilon_{\mathrm{t}-1}+\cdots+\theta \mathrm{q} \varepsilon_{\mathrm{t}-\mathrm{q}}+\varepsilon \mathrm{t}$ 
Where $y^{\prime}$ trepresents the differenced data series. The equation further indicates the lagged errors and lagged values of $y^{\prime} t$ on the right hand. This equation shows the ARIMA $(p, d, q)$, model.

Where;

$p$ denotes the order of the autoregressive (AR)

$\mathrm{d}$ denotes the degree of differencing involved (I)

$\mathrm{q}$ denotes the order of the moving average (MR)

The study used the ARIMA Model to conduct in-sample and out-of-sample forecasts of the bitcoin prices

\section{Results and Discussion}

The first step was to test the stationarity of the data. We plotted a time series plot of our data (comprising of the closing bitcoin prices between October 2013 to November 2020) which revealed that the data was not stationary as indicated in figure 1 below.

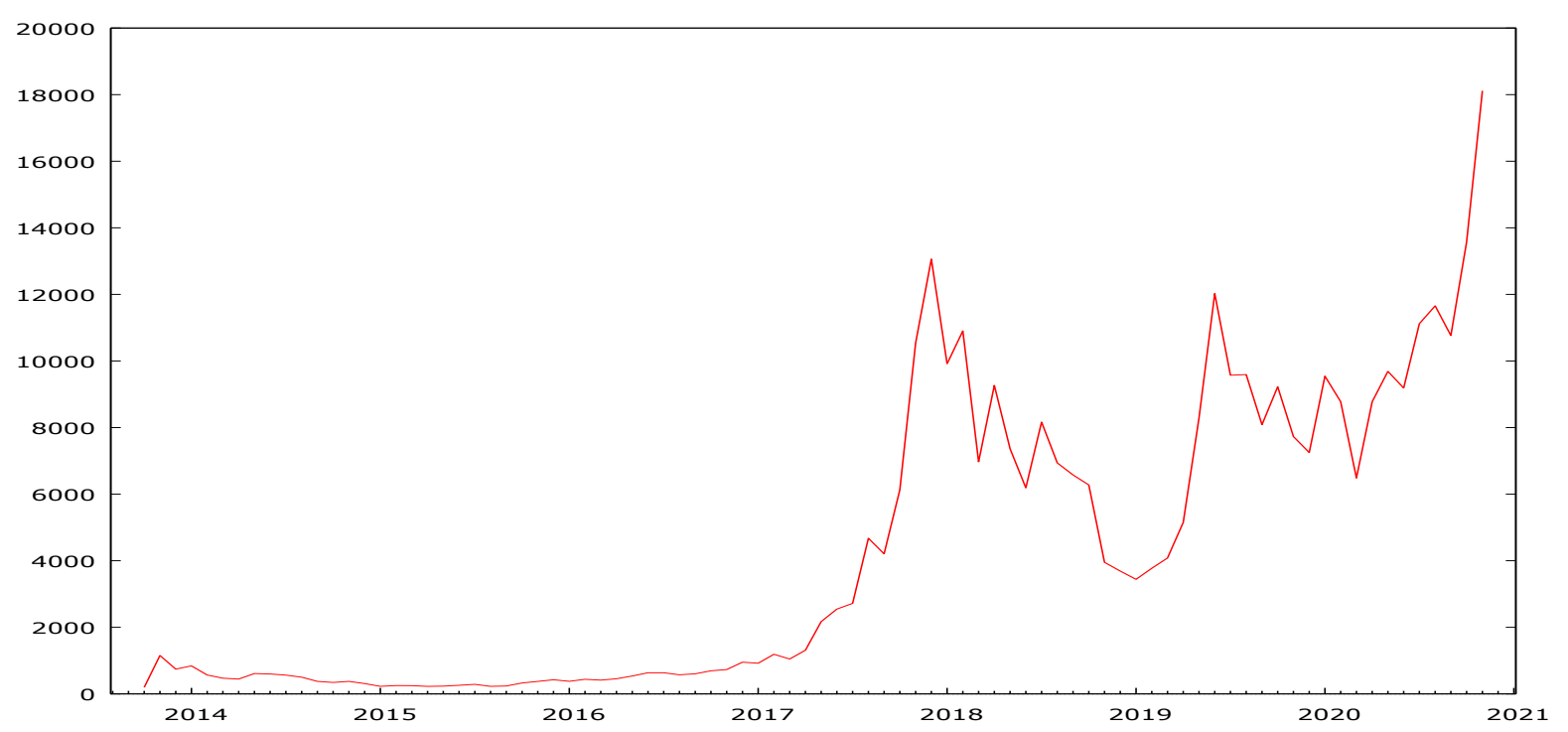

Figure 1: Time Trend of Bitcoin Prices

\subsection{ADF Unit Root Test}

For further analysis of stationarity of the data, the data was subjected to the ADF Unit Root test to test for any unit root in our time series data. The ADF Unit Root test has the following hypothesis;

Ho: No Unit Root

$\mathrm{H}_{1}$ : Unit Root

If the $p$-value $<=0.05$, this shows that the data is stationary hence reject the null hypothesis. If the $\mathrm{p}$-value $>0.05$, this shows the data has a unit root and is not stationary. In this case, you fail to reject the Null hypothesis. 
Table 1: ADF Unit Root

\begin{tabular}{|l|}
\hline Augmented Dickey-Fuller test for bitcoin prices \\
testing down from 5 lags, criterion AIC \\
sample size 85 \\
unit-root null hypothesis: a $=1$ \\
\hline test with constant \\
including 0 lags of $(1-\mathrm{L})$ bitcoinprices \\
model: $(1-\mathrm{L}) \mathrm{y}=\mathrm{b} 0+(\mathrm{a}-1)^{*} \mathrm{y}(-1)+\mathrm{e}$ \\
estimated value of $(\mathrm{a}-1): 0.0040879$ \\
test statistic: tau_c $(1)=0.108824$ \\
p-value 0.9647 \\
1st-order autocorrelation coeff. for e: -0.035 \\
\hline
\end{tabular}

From the ADF Unit Root test above, $p=0.9647>0.5$ meaning that the data is has a unit root and is not stationary thus the study fails to reject the null hypothesis. Further testing of stationarity of our time series data, we looked at the Auto Correlation Function plot also known as the Correlogram.
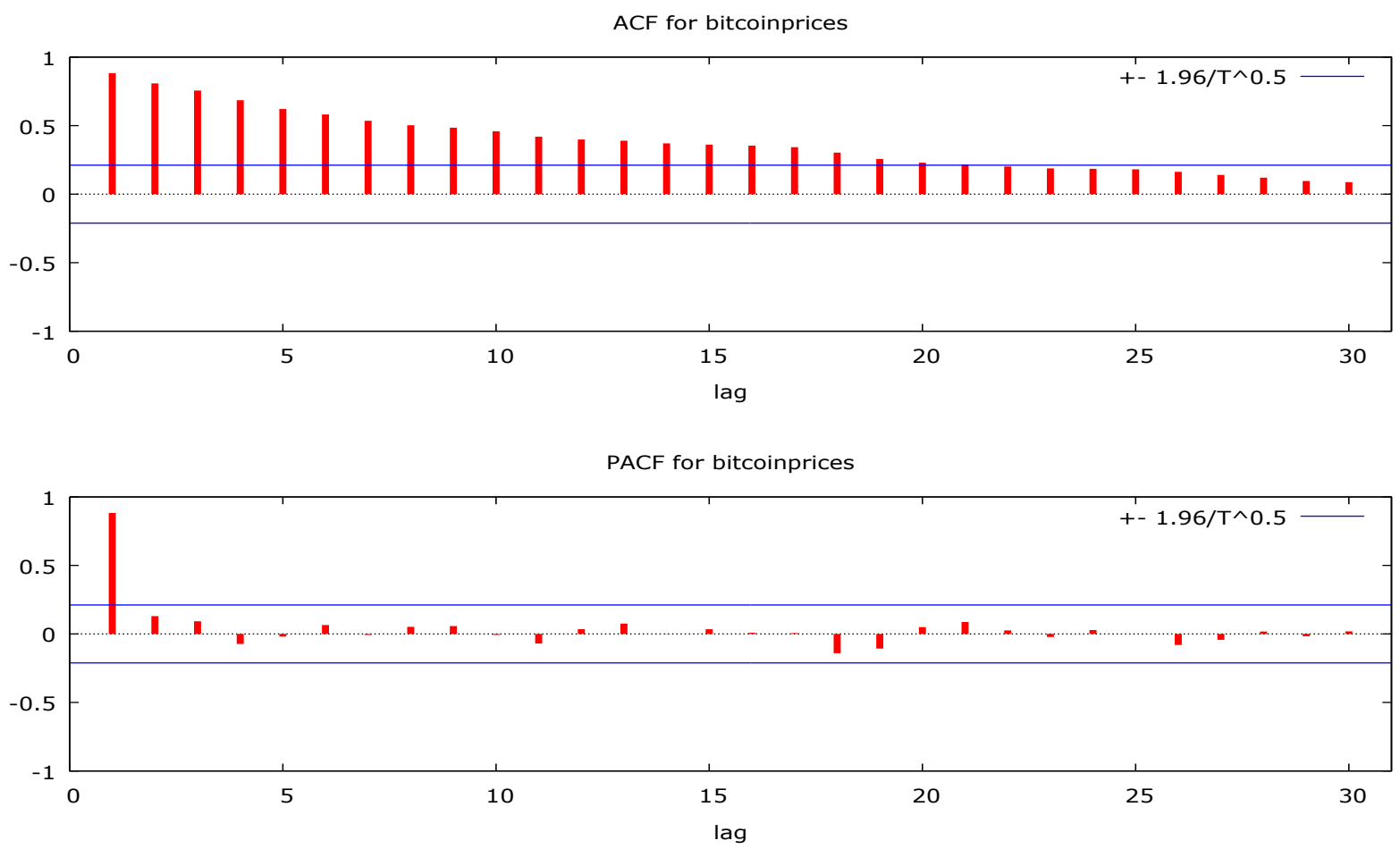

Figure 2: ACF Plot for Bitcoin Prices

The ACF graph for bitcoin prices dies exponentially decays. Also, the PACF graph for bitcoin prices dies exponentially decays with one spike cutting off after lag 1 . From figure 2 above, we can see that the data was not stationary this was further supported by table 2 below; 
Table 2: Autocorrelation Function of Bitcoin Prices

\begin{tabular}{|c|c|c|c|c|}
\hline \multicolumn{5}{|c|}{$\begin{array}{l}\text { Autocorrelation function for bitcoin prices } \\
* * *, * *, * \text { indicate significance at the } 1 \%, 5 \%, 10 \% \text { levels } \\
\text { using standard error } 1 / \mathrm{T}^{\wedge} 0.5\end{array}$} \\
\hline LAG & $\mathrm{ACF}$ & PACF & Q-stat. & [p-value] \\
\hline 1 & $0.8830^{* * *}$ & $0.8830^{* * *}$ & 69.4195 & {$[0.000]$} \\
\hline 2 & $0.8084^{* * *}$ & 0.1303 & 128.2962 & {$[0.000]$} \\
\hline 3 & $0.7559^{* * *}$ & 0.0926 & 180.3969 & {$[0.000]$} \\
\hline 4 & $0.6854^{* * *}$ & -0.0728 & 223.7484 & {$[0.000]$} \\
\hline 5 & $0.6217^{* * *}$ & -0.0189 & 259.8593 & {$[0.000]$} \\
\hline 6 & $0.5811^{* * *}$ & 0.0649 & 291.8084 & {$[0.000]$} \\
\hline 7 & $0.5352^{* * *}$ & -0.0073 & 319.2476 & {$[0.000]$} \\
\hline 8 & $0.5030^{* * *}$ & 0.0520 & 343.7996 & {$[0.000]$} \\
\hline 9 & $0.4848^{* * *}$ & 0.0575 & 366.9019 & {$[0.000]$} \\
\hline 10 & $0.4589^{* * *}$ & -0.0070 & 387.8704 & {$[0.000]$} \\
\hline 11 & $0.4195^{* * *}$ & -0.0701 & 405.6305 & {$[0.000]$} \\
\hline 12 & $0.3986^{* * *}$ & 0.0348 & 421.8818 & {$[0.000]$} \\
\hline 13 & $0.3902^{* * *}$ & 0.0754 & 437.6655 & {$[0.000]$} \\
\hline 14 & $0.3706^{* * *}$ & -0.0024 & 452.0999 & {$[0.000]$} \\
\hline 15 & $0.3613^{* * *}$ & 0.0344 & 466.0103 & {$[0.000]$} \\
\hline 16 & $0.3540^{* * *}$ & 0.0084 & 479.5592 & {$[0.000]$} \\
\hline 17 & $0.3426^{* * *}$ & 0.0063 & 492.4311 & {$[0.000]$} \\
\hline 18 & $0.3032^{* * *}$ & -0.1405 & 502.6636 & {$[0.000]$} \\
\hline 19 & $0.2566^{* *}$ & -0.1069 & 510.0985 & {$[0.000]$} \\
\hline 20 & $0.2299^{* *}$ & 0.0502 & 516.1604 & {$[0.000]$} \\
\hline 21 & $0.2159^{* *}$ & 0.0873 & 521.5896 & {$[0.000]$} \\
\hline 22 & 0.2018 * & 0.0259 & 526.4036 & {$[0.000]$} \\
\hline 23 & $0.1884^{*}$ & -0.0222 & 530.6672 & {$[0.000]$} \\
\hline 24 & $0.1849^{*}$ & 0.0288 & 534.8390 & {$[0.000]$} \\
\hline 25 & $0.1813^{*}$ & -0.0001 & 538.9165 & {$[0.000]$} \\
\hline 26 & 0.1629 & -0.0805 & 542.2634 & {$[0.000]$} \\
\hline 27 & 0.1405 & -0.0424 & 544.7951 & {$[0.000]$} \\
\hline 28 & 0.1202 & 0.0177 & 546.6814 & {$[0.000]$} \\
\hline 29 & 0.0958 & -0.0169 & 547.9012 & {$[0.000]$} \\
\hline 30 & 0.0875 & 0.0187 & 548.9349 & {$[0.000]$} \\
\hline
\end{tabular}

From Table 2 above, the ACF is statistically significant up to the $25^{\text {th }}$ lag with the first 18 lags being statically significant at $5 \%$. The PACF value of 0.8830 was also statistically significant at $5 \%$ as also indicated the possibility of a unit root making hence further confirming that the data was not stationary.

Having confirmed that the data was not stationary, the study used log transformation and differencing methods to eliminate the trend. When running a time series analysis, the data must be stationary.

\subsection{Log Transformation}

The Log transformation of our data did not reduce the skewness of the distribution as shown in Figure 3 below. 


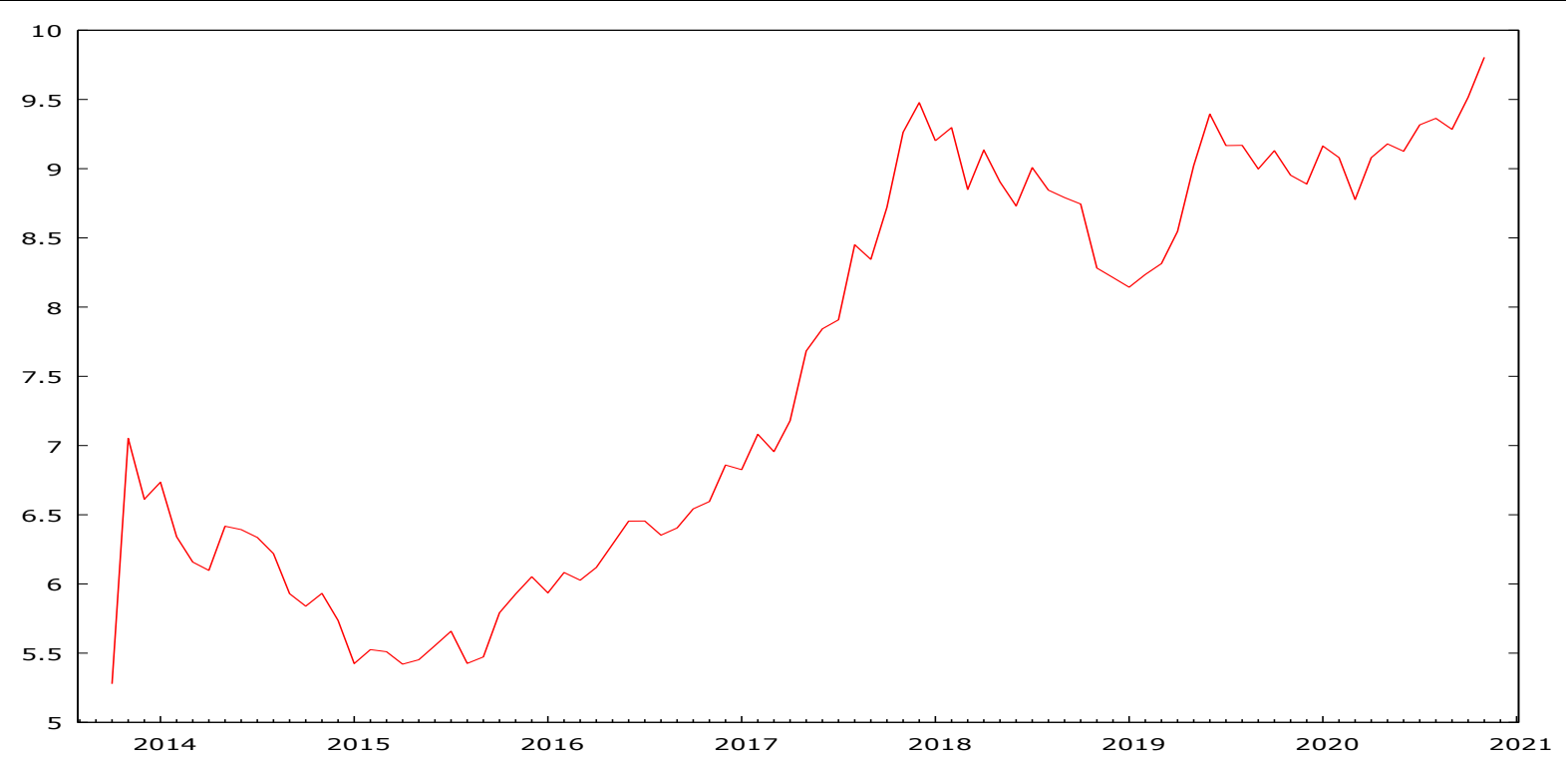

Figure 3: Log Transformation

This prompted us to use the differencing method to make the data stationary. Differencing helps to stabilize the mean of the time series data hence reducing the trend and seasonalityv . Figure 4 below shows the first difference of the bitcoin prices.

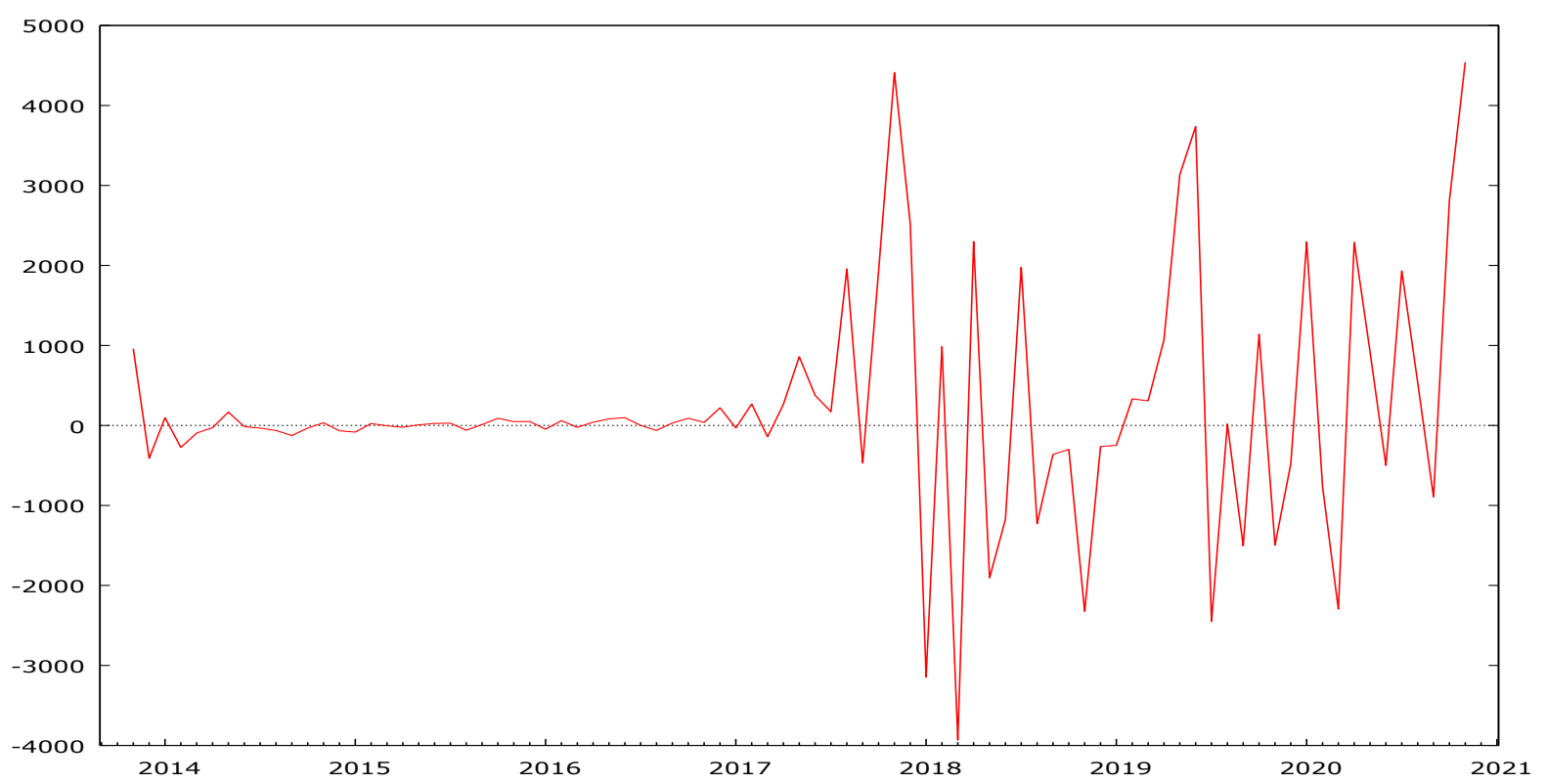

Figure 4: First Order Differencing for the Bitcoin Prices

The data was also subjected to the second-order differencing as shown in the figure below; 


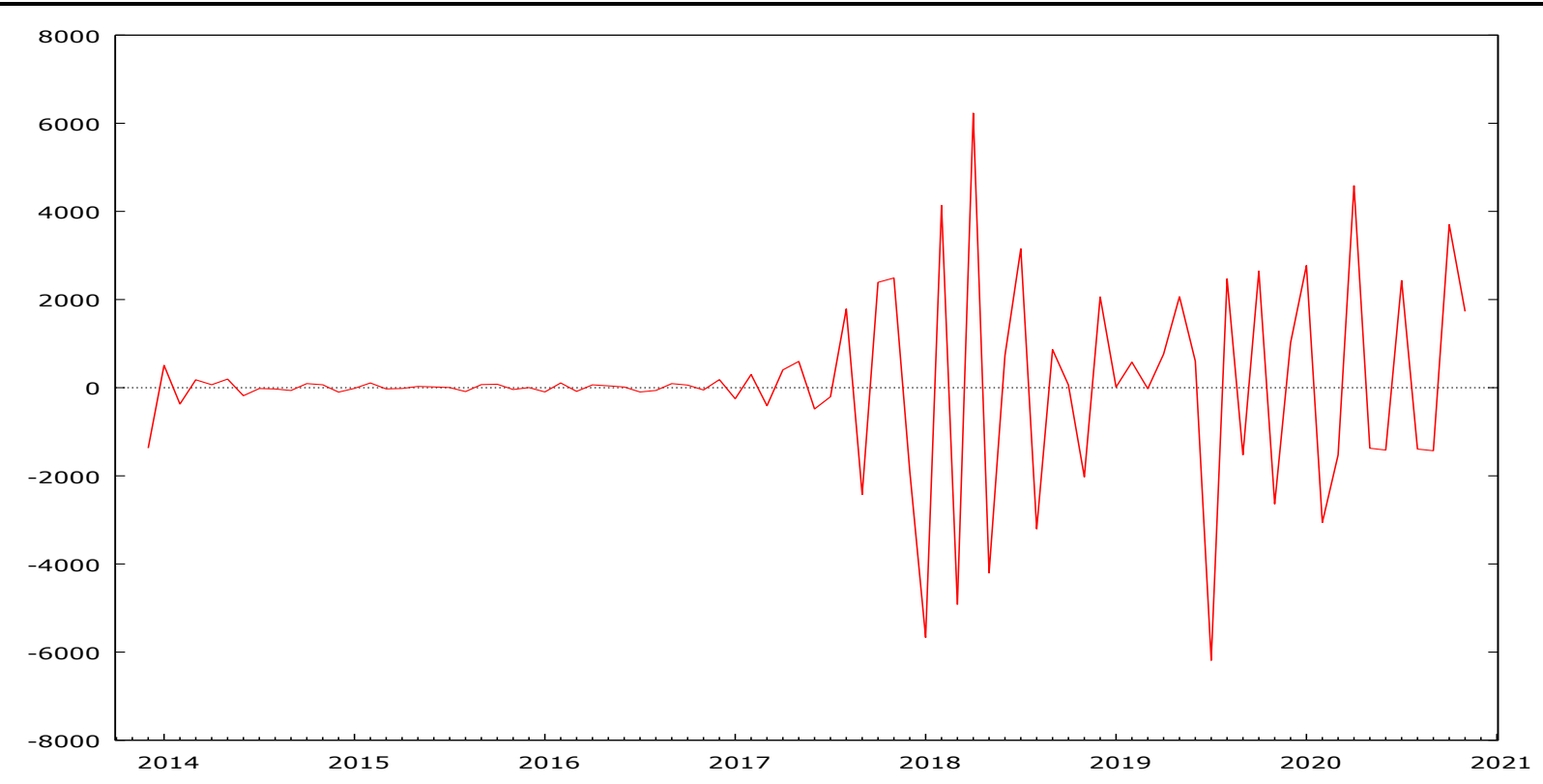

Figure 5: Second-Order Differencing for the Bitcoin Prices

\subsection{ARIMA Models}

From the correlogram (Figure 2), the AR part " $p$ " is equal to 1 and the " $q$ " is equal to 1 . To make the data series stationary, the data was differenced as shown in Figure 4 once hence the " $\mathrm{d}$ " equal to 1 . The data was further differenced as shown in Figure 5 once hence the " $d$ " equal to 2 . This gave us the ARIMA $(1,1,1)$ model with one AR term, differenced once, and one MA term. And the ARIMA $(1,2,1)$ Model with one AR term, differenced twice and one MA term.

\subsubsection{Estimating Using the ARIMA Models}

Table 3: ARIMA $(1,1,1)$ Model

\begin{tabular}{|c|c|c|c|c|c|c|}
\hline \multicolumn{7}{|c|}{$\begin{array}{l}\text { Model 1: ARIMA, using observations } 2013 \\
\text { Dependent variable: (1-L) bitcoin prices } \\
\text { Standard errors based on Hessian }\end{array}$} \\
\hline & & Coefficient & \multicolumn{2}{|c|}{ Std. Error } & $\mathbf{z}$ & p-value \\
\hline \multicolumn{2}{|c|}{ const } & 208.860 & \multicolumn{2}{|c|}{147.791} & 1.413 & 0.1576 \\
\hline \multicolumn{2}{|c|}{ phi_1 } & 0.00727026 & \multicolumn{2}{|c|}{1.37708} & 0.005279 & 0.9958 \\
\hline \multicolumn{2}{|c|}{ theta_1 } & -0.0390823 & \multicolumn{2}{|c|}{1.37520} & -0.02842 & 0.9773 \\
\hline \multicolumn{3}{|c|}{ Mean dependent var } & 210.8046 & \multicolumn{2}{|c|}{ S.D. dependent var } & 1414.132 \\
\hline \multicolumn{3}{|c|}{ Mean of innovations } & 0.278231 & \multicolumn{2}{|c|}{ S.D. of innovations } & 1405.148 \\
\hline \multicolumn{3}{|c|}{ Log-likelihood } & -736.6816 & \multicolumn{2}{|c|}{ Akaike criterion } & 1481.363 \\
\hline \multicolumn{3}{|c|}{ Schwarz criterion } & 1491.134 & \multicolumn{2}{|c|}{ Hannan-Quinn } & 1485.293 \\
\hline & & Real & Im & nary & Modulus & Frequency \\
\hline \multicolumn{7}{|l|}{ AR } \\
\hline & Root 1 & 137.546 & & & 137.5466 & 0.0000 \\
\hline \multicolumn{7}{|l|}{ MA } \\
\hline & Root 1 & 25.5870 & & & 25.5870 & 0.0000 \\
\hline
\end{tabular}


Table 4: Estimating using the ARIMA $(1,2,1)$ Model

Model 2: ARIMA, using observations 2013:12-2020:11 $(\mathrm{T}=84)$

Dependent variable: (1-L)^2 bitcoin prices

Standard errors based on Hessian

\begin{tabular}{|l|l|l|l|l|l|}
\hline & Coefficient & Std. Error & z & p-value & \\
\hline const & 8.24440 & 5.98053 & 1.379 & 0.1680 & \\
\hline phi_1 & -0.0354218 & 0.115318 & -0.3072 & 0.7587 & \\
\hline theta_1 & -1.00000 & 0.0356238 & -28.07 & $<0.0001$ & $* * *$ \\
\hline \hline
\end{tabular}

\begin{tabular}{|l|c|l|l|}
\hline \hline Mean dependent var & 42.64036 & S.D. dependent var & 1981.792 \\
\hline Mean of innovations & -55.81554 & S.D. of innovations & 1397.740 \\
\hline Log-likelihood & -729.8266 & Akaike criterion & 1467.653 \\
\hline Schwarz criterion & 1477.376 & Hannan-Quinn & 1471.562 \\
\hline \hline
\end{tabular}

\begin{tabular}{|l|l|c|c|c|c|}
\hline \hline & & Real & Imaginary & Modulus & Frequency \\
\hline AR & & & & & \\
\hline & Root 1 & -28.2312 & 0.0000 & 28.2312 & 0.5000 \\
\hline MA & & & & & \\
\hline & Root 1 & 1.0000 & 0.0000 & 1.0000 & 0.0000 \\
\hline
\end{tabular}

\subsubsection{Determining the Best ARIMA Model}

To determine the best model, we compared the coefficients, Akaike Information Criteria (AIC), and Schwarz Information Criteria (SIC) as shown in the table below;

Table 5: Comparison of the ARIMA $(1,1,1)$ and ARIMA $(1,2,1)$ Models

\begin{tabular}{|l|c|c|}
\hline & ARIMA (1,1,1) Model & ARIMA (1,2,1) Model \\
\hline Coefficients & None was statistically significant & theta_1 coefficient was statistically significant \\
\hline AIC & 1481.363 & 1467.653 \\
\hline SIC & 1491.134 & 1477.376 \\
\hline
\end{tabular}

As shown in the table above, the ARIMA $(1,2,1)$ Model had one statistically significant coefficient, the lowest AIC and SIC values. We, therefore, used this model to forecast the future of bitcoin prices. We conducted both in-sample and out-of-sample forecasts.

\subsection{In-Sample Forecast}

We conducted an in-sample forecast from October 2013-November 2019, hence reducing the number of observations to 72 . 
Table 6: ARIMA In-Sample Forecast

Model 3: ARIMA, using observations 2013:12-2019:11 $(\mathrm{T}=72)$

Dependent variable: (1-L)^2 bitcoin prices

Standard errors based on Hessian

\begin{tabular}{|l|c|c|c|c|c|}
\hline & Coefficient & Std. Error & $\mathbf{z}$ & p-value & \\
\hline const & 1.93786 & 6.74274 & 0.2874 & 0.7738 & \\
\hline phi_1 & -0.0637132 & 0.119372 & -0.5337 & 0.5935 & \\
\hline theta_1 & -1.00000 & 0.0398925 & -25.07 & $<0.0001$ & $* * *$ \\
\hline \hline
\end{tabular}

\begin{tabular}{|l|l|l|l|}
\hline \hline Mean dependent var & -34.10611 & S.D. dependent var & 1891.877 \\
\hline Mean of innovations & -11.88846 & S.D. of innovations & 1286.694 \\
\hline Log-likelihood & -619.8797 & Akaike criterion & 1247.759 \\
\hline Schwarz criterion & 1256.866 & Hannan-Quinn & 1251.385 \\
\hline
\end{tabular}

\begin{tabular}{|l|l|c|c|c|c|}
\hline \hline & & Real & Imaginary & Modulus & Frequency \\
\hline AR & & & & & \\
\hline & Root 1 & -15.6953 & 0.0000 & 15.6953 & 0.5000 \\
\hline MA & & & & & \\
\hline & Root 1 & 1.0000 & 0.0000 & 1.0000 & 0.0000 \\
\hline
\end{tabular}

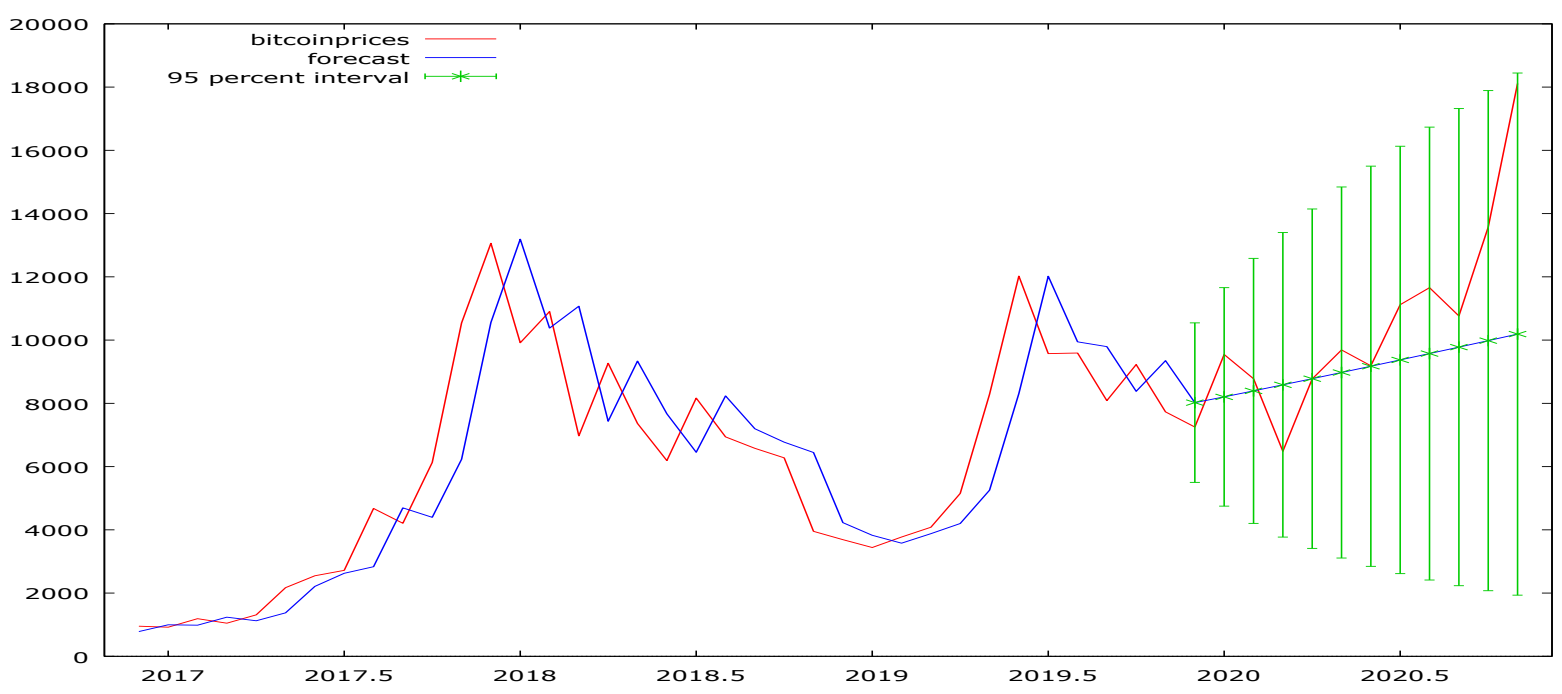

Figure 6: In-Sample Forecast of Bitcoin Prices

For $95 \%$ confidence intervals, $\mathrm{z}(0.025)=1.96$

Table 7: Bitcoin Prices In-Sample forecast

\begin{tabular}{|c|c|c|c|c|}
\hline Obs & bitcoinprices & prediction & std. error & $95 \%$ interval \\
\hline 2019:12 & 7251.28 & 8022.35 & 1286.69 & $(5500.47,10544.2)$ \\
\hline 2020:01 & 9545.08 & 8203.45 & 1762.65 & $(4748.73,11658.2)$ \\
\hline 2020:02 & 8778.47 & 8393.75 & 2137.96 & $(4203.43,12584.1)$ \\
\hline 2020:03 & 6483.74 & 8585.53 & 2456.42 & $(3771.03,13400.0)$ \\
\hline 2020:04 & 8773.11 & 8779.27 & 2738.10 & $(3412.69,14145.9)$ \\
\hline 2020:05 & 9688.32 & 8974.95 & 2993.39 & $(3108.01,14841.9)$ \\
\hline 2020:06 & 9188.06 & 9172.57 & 3228.56 & $(2844.71,15500.4)$ \\
\hline 2020:07 & 11118.9 & 9372.13 & 3447.72 & $(2614.71,16129.5)$ \\
\hline 2020:08 & 11657.0 & 9573.62 & 3653.76 & $(2412.38,16734.9)$ \\
\hline 2020:09 & 10764.3 & 9777.05 & 3848.79 & $(2233.56,17320.5)$ \\
\hline
\end{tabular}


DISRUPT AND REPLACE FIAT MONEY: THE CASE OF BITCOINS

\begin{tabular}{|l|l|l|l|l|}
\hline \hline $2020: 10$ & 13573.7 & 9982.42 & 4034.40 & $(2075.14,17889.7)$ \\
\hline $2020: 11$ & 18114.4 & 10189.7 & 4211.84 & $(1934.68,18444.8)$ \\
\hline
\end{tabular}

Forecast evaluation statistics using 12 observations

$\begin{array}{ll}\text { Mean Error } & 1325.8 \\ \text { Root Mean Squared Error } & 2761.8 \\ \text { Mean Absolute Error } & 1805.6 \\ \text { Mean Percentage Error } & 7.9841 \\ \text { Mean Absolute Percentage Error } & 15.171 \\ \text { Theil's U } & 1.075 \\ \text { Bias proportion, UM } & 0.23044 \\ \text { Regression proportion, UR } & 0.41311 \\ \text { Disturbance proportion, UD } & 0.35645\end{array}$

From the analysis above, the bitcoin prices are increasing. According to Lewis (1982), the Mean Absolute Percentage Error (MAPE) of <10 represents highly accurate forecasting, between 10-20 represents good forecasting, between 20-50 represents reasonable forecasting while $>50$ represents inaccurate forecasting.

Our in-sample forecast based on the ARIMA $(1,2,1)$ Model had a Mean Absolute Percentage Error of $15.1 \%$. This means that the model was a good forecast as the predicted prices of bitcoins vary slightly $(15 \%)$ with the actual bitcoin prices. This means that the model was $85 \%$ accurate.

Having determined that our ARIMA Model $(1,2,1)$ represented a good forecast, we went ahead and conducted an out-of-sample forecast of bitcoin prices for the next five years from December 2020 to November 2025.

\subsection{Estimating the Out-of-Sample Forecast using the ARIMA $(1,2,1)$ Model}

Table 8: ARIMA Out-of-Sample Forecast

Model 10: ARIMA, using observations 2013:12-2020:11 $(\mathrm{T}=84)$

Dependent variable: $(1-\mathrm{L})^{\wedge} 2$ bitcoin prices

Standard errors based on Hessian

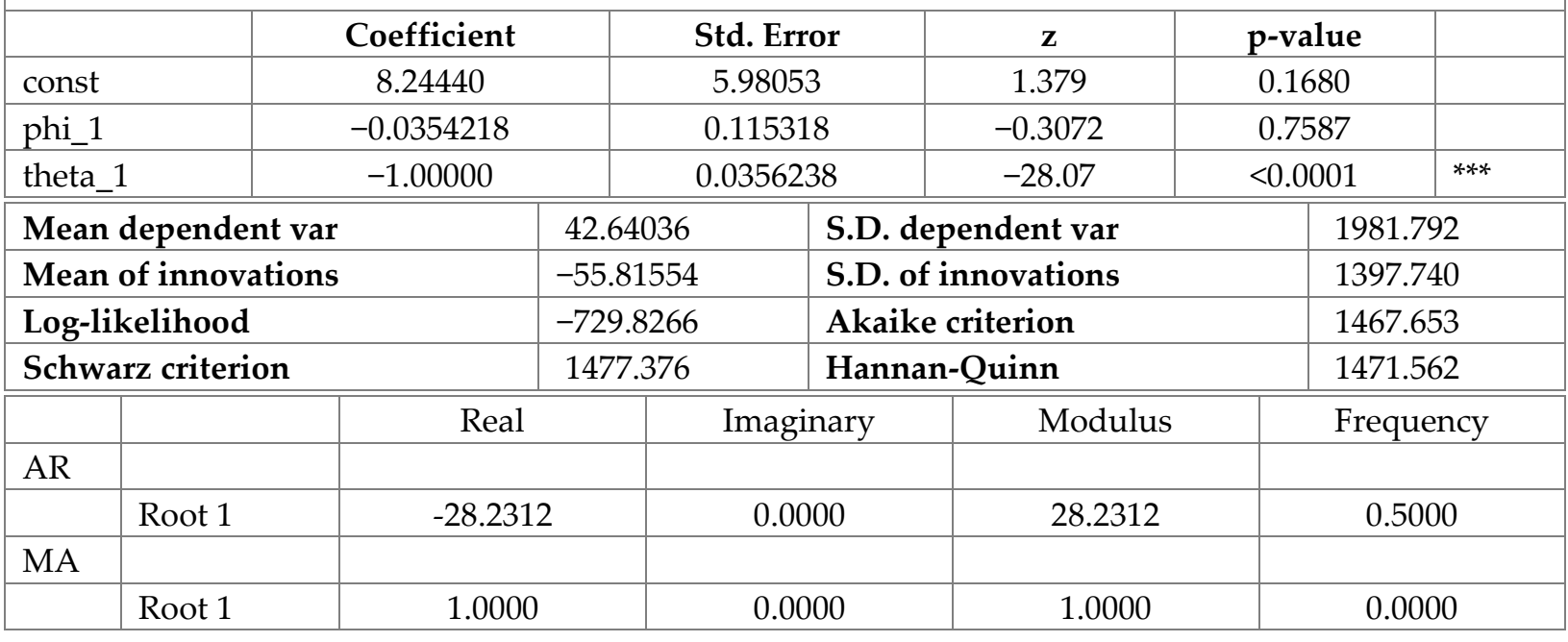


From the analysis above, the constant-coefficient is positive but not statistically significant, while the theta_1coefficient (MR) is negative and statistically significant.

\subsection{Plotting the Out-of-Sample Forecast}

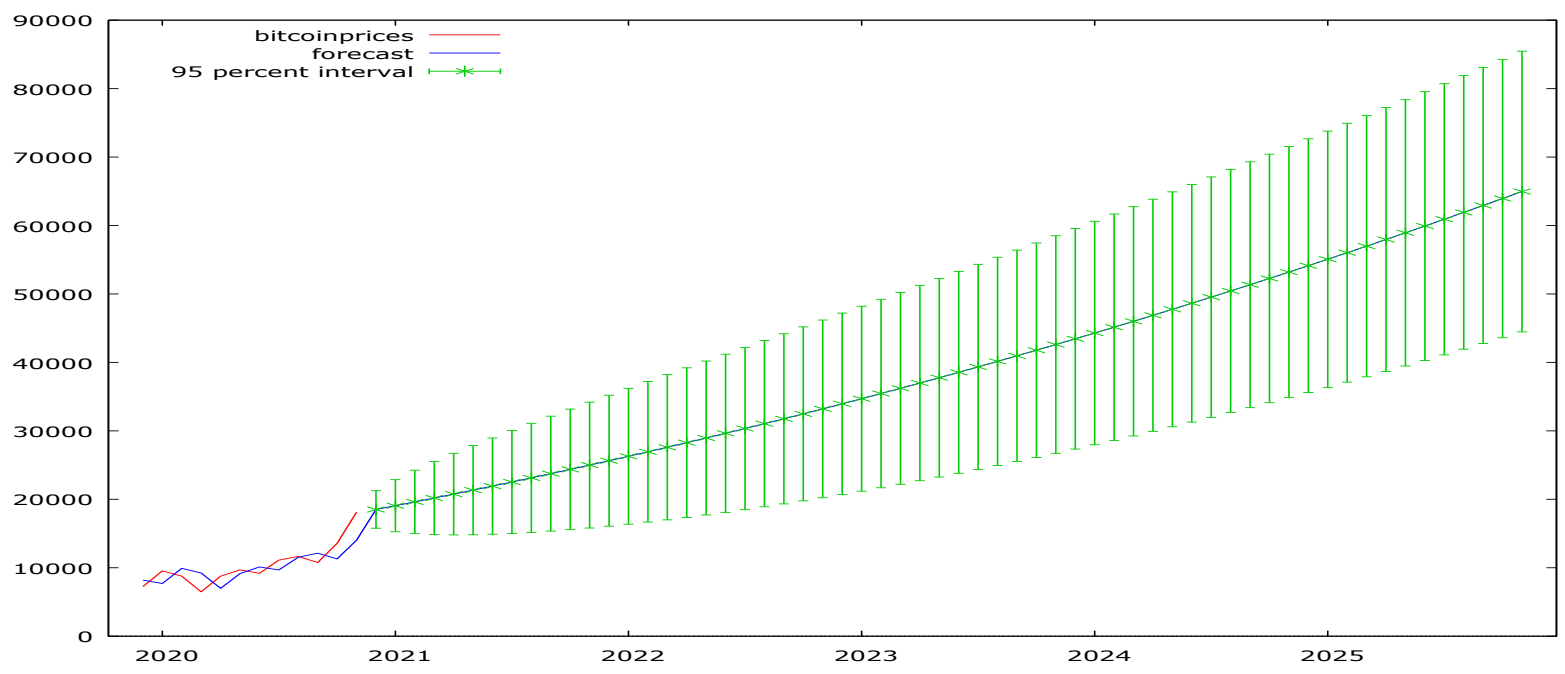

Figure 7: Out-of-Sample Forecast of Bitcoin Prices

For $95 \%$ confidence intervals, $z(0.025)=1.96$

Table 9: Bitcoin Prices Out-of-Sample Forecast

\begin{tabular}{|c|c|c|c|c|}
\hline Obs & bitcoinprices & prediction & std. error & $95 \%$ interval \\
\hline 2020:12 & undefined & 18512.3 & 1397.74 & $(15772.8,21251.9)$ \\
\hline 2021:01 & undefined & 19065.6 & 1942.01 & $(15259.3,22871.8)$ \\
\hline 2021:02 & undefined & 19621.8 & 2365.13 & $(14986.2,24257.4)$ \\
\hline 2021:03 & undefined & 20186.5 & 2723.26 & $(14849.0,25524.0)$ \\
\hline 2021:04 & undefined & 20759.4 & 3039.48 & $(14802.2,26716.7)$ \\
\hline 2021:05 & undefined & 21340.6 & 3325.77 & $(14822.2,27859.0)$ \\
\hline 2021:06 & undefined & 21930.0 & 3589.30 & $(14895.1,28964.9)$ \\
\hline 2021:07 & undefined & 22527.7 & 3834.76 & $(15011.7,30043.7)$ \\
\hline 2021:08 & undefined & 23133.6 & 4065.42 & $(15165.5,31101.6)$ \\
\hline 2021:09 & undefined & 23747.7 & 4283.68 & $(15351.8,32143.6)$ \\
\hline 2021:10 & undefined & 24370.1 & 4491.35 & $(15567.2,33173.0)$ \\
\hline 2021:11 & undefined & 25000.7 & 4689.84 & $(15808.8,34192.6)$ \\
\hline 2021:12 & undefined & 25639.6 & 4880.25 & $(16074.5,35204.7)$ \\
\hline 2022:01 & undefined & 26286.7 & 5063.51 & $(16362.4,36211.0)$ \\
\hline 2022:02 & undefined & 26942.1 & 5240.37 & $(16671.2,37213.0)$ \\
\hline 2022:03 & undefined & 27605.7 & 5411.45 & $(16999.5,38212.0)$ \\
\hline 2022:04 & undefined & 28277.6 & 5577.28 & $(17346.3,39208.8)$ \\
\hline 2022:05 & undefined & 28957.7 & 5738.33 & $(17710.8,40204.6)$ \\
\hline 2022:06 & undefined & 29646.0 & 5894.97 & $(18092.1,41200.0)$ \\
\hline 2022:07 & undefined & 30342.6 & 6047.56 & $(18489.6,42195.6)$ \\
\hline 2022:08 & undefined & 31047.4 & 6196.40 & $(18902.7,43192.2)$ \\
\hline 2022:09 & undefined & 31760.5 & 6341.74 & $(19330.9,44190.1)$ \\
\hline 2022:10 & undefined & 32481.8 & 6483.82 & $(19773.8,45189.9)$ \\
\hline 2022:11 & undefined & 33211.4 & 6622.86 & $(20230.8,46192.0)$ \\
\hline
\end{tabular}


Virginia Kirigo Wachira, Esther Wanjiru Wachira

DIGITAL CURRENCIES AND THEIR POTENTIAL TO

DISRUPT AND REPLACE FIAT MONEY: THE CASE OF BITCOINS

\begin{tabular}{|c|c|c|c|c|}
\hline 2022:12 & undefined & 33949.2 & 6759.04 & $(20701.7,47196.7)$ \\
\hline 2023:01 & undefined & 34695.3 & 6892.53 & $(21186.2,48204.4)$ \\
\hline 2023:02 & undefined & 35449.6 & 7023.48 & $(21683.8,49215.3)$ \\
\hline 2023:03 & undefined & 36212.1 & 7152.03 & $(22194.4,50229.8)$ \\
\hline 2023:04 & undefined & 36982.9 & 7278.31 & $(22717.7,51248.1)$ \\
\hline 2023:05 & undefined & 37761.9 & 7402.44 & $(23253.4,52270.5)$ \\
\hline 2023:06 & undefined & 38549.2 & 7524.53 & $(23801.4,53297.0)$ \\
\hline 2023:07 & undefined & 39344.7 & 7644.66 & $(24361.5,54328.0)$ \\
\hline 2023:08 & undefined & 40148.5 & 7762.93 & $(24933.4,55363.6)$ \\
\hline 2023:09 & undefined & 40960.5 & 7879.43 & $(25517.1,56403.9)$ \\
\hline 2023:10 & undefined & 41780.8 & 7994.23 & $(26112.4,57449.2)$ \\
\hline 2023:11 & undefined & 42609.3 & 8107.41 & $(26719.0,58499.5)$ \\
\hline 2023:12 & undefined & 43446.0 & 8219.03 & $(27337.0,59555.0)$ \\
\hline 2024:01 & undefined & 44291.0 & 8329.15 & $(27966.2,60615.8)$ \\
\hline 2024:02 & undefined & 45144.2 & 8437.84 & $(28606.4,61682.1)$ \\
\hline 2024:03 & undefined & 46005.7 & 8545.14 & $(29257.5,62753.9)$ \\
\hline 2024:04 & undefined & 46875.4 & 8651.11 & $(29919.6,63831.3)$ \\
\hline 2024:05 & undefined & 47753.4 & 8755.80 & $(30592.3,64914.5)$ \\
\hline 2024:06 & undefined & 48639.6 & 8859.26 & $(31275.8,66003.4)$ \\
\hline 2024:07 & undefined & 49534.1 & 8961.51 & $(31969.8,67098.3)$ \\
\hline 2024:08 & undefined & 50436.8 & 9062.62 & $(32674.4,68199.2)$ \\
\hline 2024:09 & undefined & 51347.7 & 9162.61 & $(33389.3,69306.1)$ \\
\hline 2024:10 & undefined & 52266.9 & 9261.52 & $(34114.6,70419.1)$ \\
\hline 2024:11 & undefined & 53194.3 & 9359.38 & $(34850.3,71538.4)$ \\
\hline 2024:12 & undefined & 54130.0 & 9456.24 & $(35596.1,72663.9)$ \\
\hline 2025:01 & undefined & 55073.9 & 9552.11 & $(36352.1,73795.7)$ \\
\hline 2025:02 & undefined & 56026.1 & 9647.02 & $(37118.3,74933.9)$ \\
\hline 2025:03 & undefined & 56986.5 & 9741.02 & $(37894.5,76078.5)$ \\
\hline 2025:04 & undefined & 57955.1 & 9834.11 & $(38680.6,77229.7)$ \\
\hline 2025:05 & undefined & 58932.0 & 9926.33 & $(39476.8,78387.3)$ \\
\hline 2025:06 & undefined & 59917.2 & 10017.7 & $(40282.8,79551.5)$ \\
\hline 2025:07 & undefined & 60910.6 & 10108.3 & $(41098.8,80722.4)$ \\
\hline 2025:08 & undefined & 61912.2 & 10198.0 & $(41924.5,81899.9)$ \\
\hline 2025:09 & undefined & 62922.1 & 10287.0 & $(42760.0,83084.2)$ \\
\hline 2025:10 & undefined & 63940.2 & 10375.2 & $(43605.3,84275.1)$ \\
\hline 2025:11 & undefined & 64966.6 & 10462.6 & $(44460.2,85472.9)$ \\
\hline
\end{tabular}

The prices of bitcoin will continue increasing and within the 95\% confidence level. However, the increase in prices will not have a significant impact.

\section{Conclusion and Recommendation}

This study stated the question of whether Bitcoin is disruptive to replace fiat money. An interesting observation is that advancement in technology and changes in customer behavior, tastes, and preferences are aspects that businesses cannot ignore in today's era. Findings show that technology advancement has eliminated the central authority and new markets are created hence expanding currency exchange services and how 
businesses are conducted and run. However, the study reveals that technological advancement has seen the emergence of digital currencies with Bitcoin being the most conspicuous and widely recognized digital currency.

As indicated in the literature, money serves three major functions namely; medium of exchange, unit of account and store of value. One finding that stands out is that the numerous implications of bitcoin fail to meet all the functions of money. Most notably, as a medium of exchange, bitcoin has seen a gradual rise in acceptance as a means of payment. However, the majority of the big and established companies still reject the acceptance of payment through bitcoins. This can be attributed to its lack of centralization. Secondly, bitcoins fail as a unit of account particularly due to their high price volatility. Bitcoin fails as a store of value due to the lack of regulation and cyberattacks.

Empirical findings reveal that most researchers view bitcoins as disruptive innovations. Nevertheless, based on Christensen (1997), Christensen, et al., (2015), this study concludes that bitcoins are neither disruptive innovations nor disruptive technologies mainly because; First, according to Nakamato (2009), bitcoin was created as a peer to peer version of electronic cash which would enable direct payments to form one person to another. The main purpose of the bitcoin was to eliminate the role of intermediaries during money transfers. However, this is not different from the functions of mobile money. For instance, M-Pesa in Kenya which was introduced in 2007 enables customers to transfer, save, and receive money and also make payments using their mobile phones. Secondly, looking product life cycle of disruptive technologies or innovation, in terms of functionality, bitcoin transfer of money and also some traders are accepting payment of merchandise in terms of bitcoins. In terms, of convenience, the lack of intermediaries makes transactions speedy and more convenient. However, bitcoin fails in terms of reliability since it is prone to hackers and is highly volatile. Third, according to Christensen et al., (2015), disruptive innovations start to form a "low-end or newmarket" targeting an ignored segment and are considered as inferior innovations by the existing companies and their customers. This is not the case with bitcoin. The initial purpose of the bitcoin was not to target any ignored customer base but rather to eliminate intermediaries. According to Nakamato, (2009), the initial intention was to allow two willing parties to directly transact with each other without a third party. Finally, disruptive innovations according to Christensen et al., (2015) end up replacing the established businesses. This view can't hold in terms of bitcoin since bitcoin has a limited of 21 million (Gilbert \& Loi, 2018), which according to Ciaian et al., (2018), will be reached by 2041.

Bitcoins do not have the potential to completely replace fiat money. Findings from the ARIMA model forecast that bitcoins prices will gradually increase. A price increase can be due to an increase in demand. However, this increase in the bitcoin prices is not significant. The insignificance of the price increase can be attributed to the high risks associated with the bitcoins such as high price volatility, lack of regulation, and cyberattacks. The only way in which digital currencies can compete with Fiat money is through 
the introduction of centralized digital currencies as Governments are not very keen on losing their control over fiat money.

China through the People's Bank of China launched its digital currency the digital Yuan recently. The study, therefore, recommends further studies on the potential impact of Central banks' digital currencies on National and Global currencies.

\section{Conflict of Interest Statement}

The authors declare no conflicts of interests.

\section{About the Authors}

Virginia Kirigo Wachira holds a bachelor degree in Accounting and Economics from Nairobi University (Kenya), Master in Business Administration-Finance Option from Kenyatta University (Kenya) and has currently completed her Ph.D. Business Administration- Finance Option from Kabarak University (Kenya) awaiting graduation. She has a vast experience in lecturing Institutions of Higher learning and Universities in Kenya. Her main areas of interest are Financial Statement Analysis, Money and Banking, Financial Innovations, Fintech and Financial Accounting among others.

Esther Wanjiru Wachira holds a bachelor degree in Business Computing from Makerere University (Uganda), Master in Business Administration-Finance Option from Kenyatta University (Kenya), and is currently pursuing her Ph.D. Business Administration from University of Pecs (Hungary). Her main areas of interest are Fintech, Block chains, Cryptocurrencies and Financial Innovations.

\section{References}

Abramova S, Böhme R, 2016. Perceived benefit and risk as multidimensional determinants of bitcoin use: A quantitative exploratory study. International Conference on Information Systems, ICIS 2016, Zohar 2015, 1-20. doi: 10.17705/4icis.00001

Ally M, Gardiner M, Lane M, 2015. The Potential Impact of Digital Currencies on the Australian Economy. Australasian Conference on Information Systems.

Böhme R, Christin N, Edelman B, Moore T, 2015. Bitcoin: Economics, Technology, and Governance. 29(2), 213-238.

Brunnermeier M.K, James H, 2019. The Digitalization of Money. NBER Working Paper No. $263001-31$.

Chan S, Chu J, Nadarajah S, Osterrieder J, 2017. A Statistical Analysis of Cryptocurrencies. Journal of Risk and Financial Management, 10(2), 12. doi: 10.3390/jrfm10020012

Christensen C. M, 1997. Innovator's Dilemma in Business. When New Technologies Cause Great Firms to Fail. Harvard Business School Press. 
Ciaian P, Rajcaniova M, \& Kancs d'Artis, 2016. The economics of BitCoin price formation. Applied Economics, 48(19), 1799-1815. doi:10.1080/00036846.2015.1109038

Ciaian P, Rajcaniova M, \& Kancs, d'Artis. 2018. Virtual relationships: Short- and long-run evidence from BitCoin and altcoin markets. Journal of International Financial Markets, Institutions and Money, 52, 173-195. doi:.10.1016/j.intfin.2017.11.001

Danneels E, 2004. Disruptive Technology Reconsidered: A Critique and Research Agenda. Journal of Product Innovation Management 21 pp 246-258

Dwyer G.P, 2014. The Economics of Bitcoin and Similar Private Digital Currencies. Munich Personal RePEc Archive 57360.

EBA. 2014. EBA Opinion on 'virtual currencies' (Issue July).

Eigbe O. E, 2018. Investigating the Levels of Awareness and Adoption of Digital Currency in Nigeria: a Case Study of Bitcoin. Information Technologist, 15(1), 75. http://search.ebscohost.com/login.aspx?direct=true\&AuthType=cookie,ip,uid\&db $=$ edb\&AN=131994334\&amp\%0Alang=de\&site=eds-live\&authtype=uid\&lang=de

European Central Bank. 2015. Virtual currency schemes - a further analysis. In European

Central Bank (Issue February). http://www.ecb.europa.eu/pub/pdf/other/virtualcurrencyschemes201210en.pdf

Faulkner P, Runde, J 2014. "The Social, the material, and the ontology of non-material technological objects ». May.

Fiammetta D, Piazza S, 2017. Bitcoin and the Blockchain as Possible Corporate Governance Tools: Strengths and Weaknesses. Bocconi Legal Papers, 9, 5(2), 125156.

Frascaroli B. F, (2019). Bitcoin's innovative aspects, return volatility and uncertainty shocks. October.

Gilbert S, Loi H, 2018. Digital Currency Risk. International Journal of Economics and Finance, 10(2), 108. doi:10.5539/ijef.v10n2p108

Giudici G, Milne A, Vinogradov D, 2020. Cryptocurrencies: market analysis and perspectives. Journal of Industrial and Business Economics, 47(1), 1-18. doi:10.1007/s40812-019-00138-6

Giungato P, 2017. Current Trends in Sustainability of Bitcoins and Related Blockchain Technology. doi:10.3390/su9122214

Latzer M, 2009. Information and communication technology innovations: Radical and disruptive?. New Media \& Society 11. 599-619. 10.1177/1461444809102964.

Markides C, 2006. Disruptive Innovation: In Need of Better Theory. Journal of Product Innovation Management 23 pp 19-25

Moore T, 2013. The promise and perils of digital currencies. International Journal of Critical Infrastructure Protection, 6(3-4), 147-149. doi:10.1016/j.ijcip.2013.08.002

Nakamato S, 2009. Bitcoin: A Peer-to Peer Electronic Cash System. 1-9. https://bitcoin.org/bitcoin.pdf

Narayanan H, 2020. Is Future a Rule of Digital Currency ??? International Journal of Research, 8, 96-106. doi:10.29121/granthaalayah.v8.i8.2020.935 
Nelson B, 2018. Financial stability and monetary policy issues associated with digital currencies. Journal of Economics and Business, 100(December 2017), 76-78. doi:10.1016/j.jeconbus.2018.06.002

Peters G. W, Panayi E, 2016. Understanding modern banking ledgers through blockchain technologies: Future of transaction processing and smart contracts on the internet of money. New Economic Windows, 239-278. doi:10.1007/978-3-319-42448-4_13

Presthus W, O'Malley N. O, 2017. Motivations and Barriers for End-User Adoption of Bitcoin as Digital Currency. Procedia Computer Science, 121, 89-97. doi:10.1016/j.procs.2017.11.013

Robleh A, Barrdear J, Roger C, Southgate J, 2014. Bank of England Quarterly Bulletin 2014 Q3. 1, 276-286.

Rose C, 2015. The Evolution Of Digital Currencies : Bitcoin , A Cryptocurrency Causing A Monetary Revolution. International Business \& Economics Research Journal, 14(4), 617-622.

Roussou I, Stiakakis E, 2016. Adoption of Digital Currencies by Companies in the European Union: A Research Model combining DOI and TAM. 4th International Conference on Contemporary Marketing Issues (ICCMI) 2016, June 2016, 163-168.

Saito K, Iwamura M, 2019. How to make a digital currency on a blockchain stable. Future Generation Computer Systems, 100, 58-69. doi.10.1016/j.future.2019.05.019

Stevens A, 2017. Digital currencies: Threats and opportunities for monetary policy. Economic Review, I, 79-92.

Tatjana B, 2018. Blockchain and Digital Currency in the World of Finance (pp. 1-17).

White R, Marinakis Y, Islam N, Walsh S, 2020. Is Bitcoin a currency, a technology-based product, or something else? Technological Forecasting and Social Change, 151 (November 2019). doi:10.1016/j.techfore.2019.119877

Wu C. Y, Pandey V. K, 2014. The Value of Bitcoin in Enhancing the Efficiency of an Investor's Portfolio. Journal of Financial Planning, 27(9), 44-52.

Yermack D, 2013. Is Bitcoin a Real Currency? An economic appraisal. In NBER Working Paper No. 19747.

Yu D, \& Hang C.C, 2010. A Reflective Review of Disruptive Innovation Theory. International Journal of Management Reviews, Vol. 12, 435-452. 
Authors will retain copyright to their published articles agreeing that a Creative Commons Attribution 4.0 International License (CC BY 4.0) terms will be applied to their work. Under the terms of this license, no permission is required from the author(s) or publisher for members of the community to copy, distribute, transmit or adapt the article content, providing a proper, prominent and unambiguous attribution to the authors in a manner that makes clear that the materials are being reused under permission of a Creative Commons License. Views, opinions and conclusions expressed in this research article are views, opinions and conclusions of the author(s). Open Access Publishing Group and European Journal of Economic and Financial Research shall not be responsible or answerable for any loss, damage or liability caused in relation to/arising out of conflict of interests, copyright violations and inappropriate or inaccurate use of any kind content related or integrated on the research work. All the published works are meeting the Open Access Publishing requirements and can be freely accessed, shared, modified, distributed and used in educational, commercial and non-commercial purposes under a Creative Commons Attribution 4.0 International License (CC BY 4.0). 